\title{
Original
}

\section{Afectación ungueal de origen ocupacional}

\section{Nail involvement of occupational origin}

\section{Carmen Karina Guzmán Vera'; Margaret Karen Baldeon Santos², Ana Rita Rodrigues Barata ${ }^{3}$, Luis Conde-Salazar Gómez ${ }^{3}$}

1. Hospital Universitario de Fuenlabrada. Fuenlabrada (Madrid). España.

2. Mutua Universal. Madrid. España.

3. Servicio de Dermatología Laboral. Escuela Nacional de Medicina del Trabajo. Instituto de Salud Carlos III. Madrid. España.

Recibido: 07-08-12

Aceptado: 05-10-12

\section{Correspondencia}

Luis Conde-Salazar Gómez

Instituto de Salud Carlos III

Escuela Nacional de Medicina del Trabajo

Pabellón, 8 Ciudad Universitaria

28040 Madrid. España

Tfno: 918224045

Correo electrónico: Iconde@isciii.es

\section{ResUmen}

Desde el siglo V a.C. Hipócrates ya describía las afectaciones ungueales, las cuales luego se relacionaban con enfermedades sistémicas o adquiridas. Los médicos de medicina del trabajo se deben preparar para detectar las afectaciones por factores externos. Sin embargo son pocos los casos publicados sobre patología ungueal de origen ocupacional.

Nuestra revisión consiste en brindar conocimientos básicos sobre esta asignatura. Desde su definición, función y la descripción de su anatomía. La patología ungueal la clasificaremos según: a) anomalías de: la forma, de la adhesión, de la coloración, superficie, infección; b) según el mecanismo de acción que se producen o c) según el tipo de ocupación.

Al adquirir estos conocimientos podremos establecer posteriores pautas de prevención eficaces.

Med Segur Trab (Internet) 2012; 58 (229) 321-326

Palabras clave: Patología ungueal, lúnula, uña traumática, matriz ungueal, onicodistrofia lamelar.

Abstract

From the V century B.C. Hippocrates described the damages in the nails, which then were related to systemic diseases or acquired. As physicians we must prepare work to detect the effects caused by external factors. However, few published cases of occupational origin nail pathology. Our review is to provide basic knowledge on this subject. From its definition, function and description of the anatomy. The nail pathology classify as: a) anomalies: the way of accession, coloration, surface, infection, b) according to the mechanism of action that occur oc) by type of occupation. By acquiring this knowledge we can establish effective prevention guidelines later.

Med Segur Trab (Internet) 2012; 58 (229) 321-326

Key words: pathology nail, lunula, nail trauma, nail matrix, lamellar onychodystrophy. 


\section{INTRODUCCIÓN}

Las uñas son órganos de protección situados en los dedos de manos y pies. Aproximadamente el diez por ciento de todos los problemas de piel son causados por desórdenes ungueales. Ocurre de forma similar tanto en hombres como en mujeres y aumenta con la edad ${ }^{1}$. Su examen puede aportar importantes claves para el diagnóstico de enfermedades subyacentes. Las lesiones ungueales ya fueron descritas por Hipócrates en el siglo $\mathrm{V}$ a.C. ${ }^{1} \mathrm{y}$ desde entonces, múltiples alteraciones ungueales han sido relacionadas con enfermedades sistémicas y también de causa adquirida ${ }^{2}$.

Dentro de las causas adquiridas están las de origen ocupacional, las cuales son de nuestro especial interés, ya que en el mundo laboral son las manos y uñas las que se encuentran principalmente en contacto con los diferentes tipos de agentes externos (biológicos, químicos, traumáticos,...) según el tipo de actividad que realicen.

La uña es una estructura anatómica compleja, que con la evolución natural de la raza humana se sustituyó su función primitiva de aprehensión y captura de la presa por otra mucho más sofisticada: aumentar la sensibilidad del pulpejo y permitir trabajos de precisión ${ }^{3}$.

La función de la epidermis es formar la superficie o capa córnea de la piel; su principal componente es la queratina. En ciertas áreas el epitelio se desarrolla en forma especial para producir un tipo particular de estructura de la queratina como sucede en el pelo y las uñas.

El cuerpo de la uña está formado en parte por el epitelio de la matriz y en parte por el lecho ungueal. Una fina capa córnea denominada cutícula sirve para sellar el espacio periungueal y se extiende desde el pliegue ungueal hasta el lecho de la uña. La "lamina ungueal" es el producto córneo final del elemento epidérmico más importante, la matriz; se encuentra delimitada por tres pliegues: dos laterales y uno proximal, aunque se puede considerar un cuarto, el distal, que limita con el borde libre de la uña con el pulpejo, denominado hiponiquio. En la porción proximal hay un arco denominado "lúnula" (figura 1).

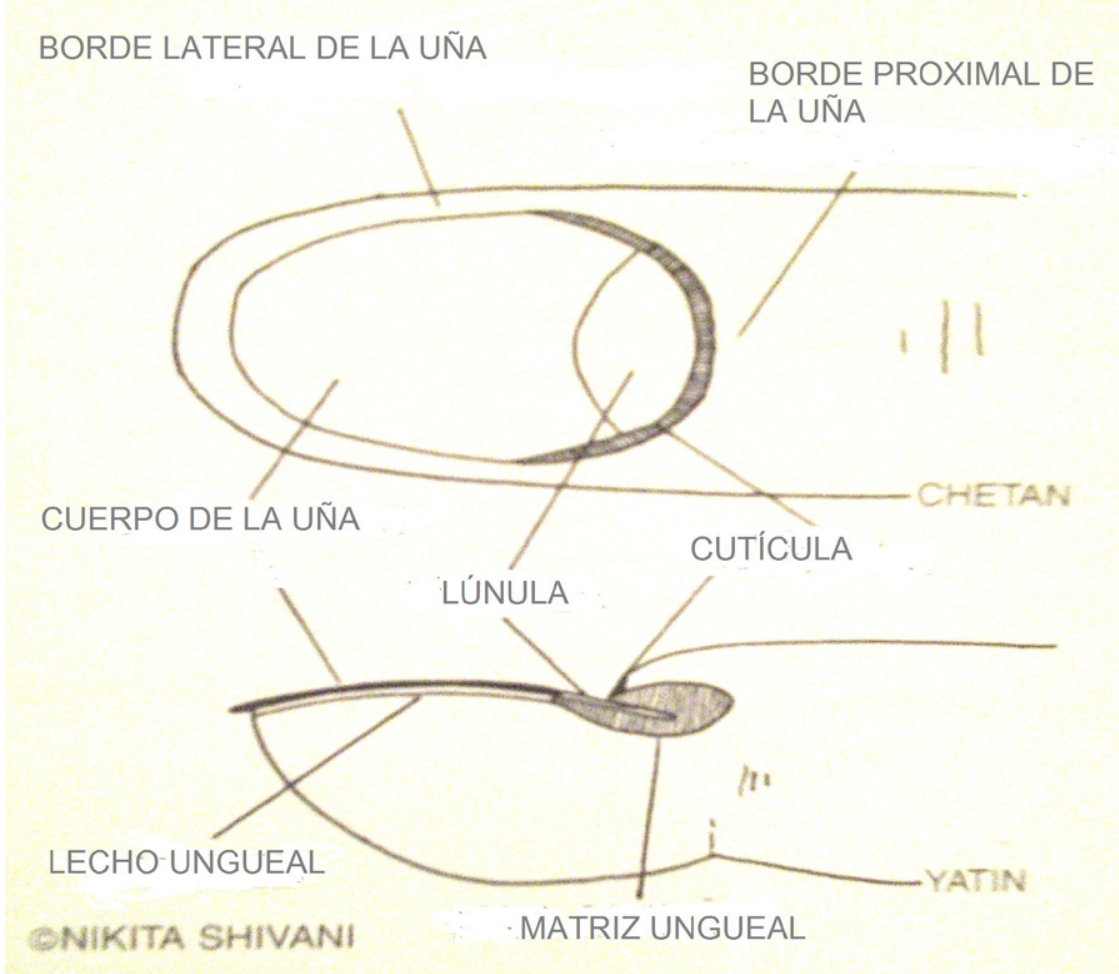

Tomado del artículo "Hand Dermatitis and Nail Disorders of the workplace". Clin Occup Environ Med" 
Todas las afecciones o los agentes (físicos, químicos, biológicos) que actúan sobre la matriz de la uña, van a originar una afectación ungueal que en muchas ocasiones puede ser permanente.

Son pocos los casos publicados acerca de las alteraciones ungueales de origen profesional, entre ellos encontramos: "Distrofia ungueal por quaternion 15 y metacrilatos" "Onicodistrofia lamelar asociada a la hoja de Te" ${ }^{8}$, "Paroniquia crónica en a nivel de lecho ungueal en trabajador de cafetal" ${ }^{9}$, etc.

\section{ALTERACIONES UNGUEALES}

Entre las más frecuentes podemos mencionar (Tabla I):

\section{Anomalias de la forma:}

Coiloniquia: Consiste en el desarrollo de una curvatura inversa del eje transversal y longitudinal, por lo que las uñas son delgadas y cóncavas de lado a lado con bordes invertidos (figura 2)

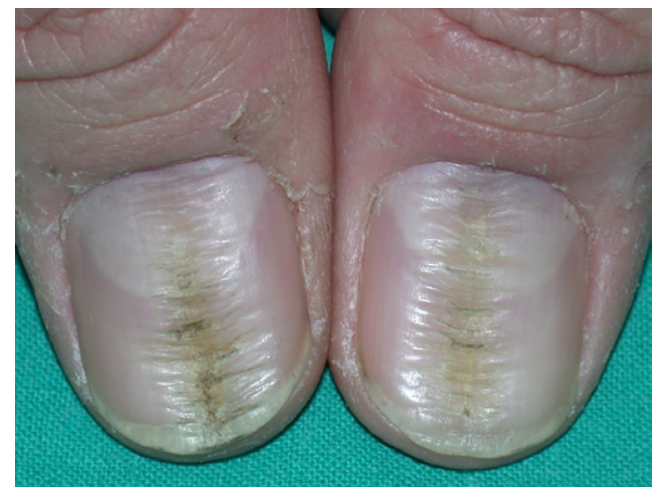

Anomalías de la adbesión:

Onicolisis: Separación distal y/ o lateral del cuerpo de la uña del lecho ungueal que progresa hasta la porción proximal. Las áreas de separación aparecen de color blanquecino o amarillento debido a la presencia de aire debajo de las uñas, detritus, a la descamación y al exudado de glicoproteínas (figura 3).

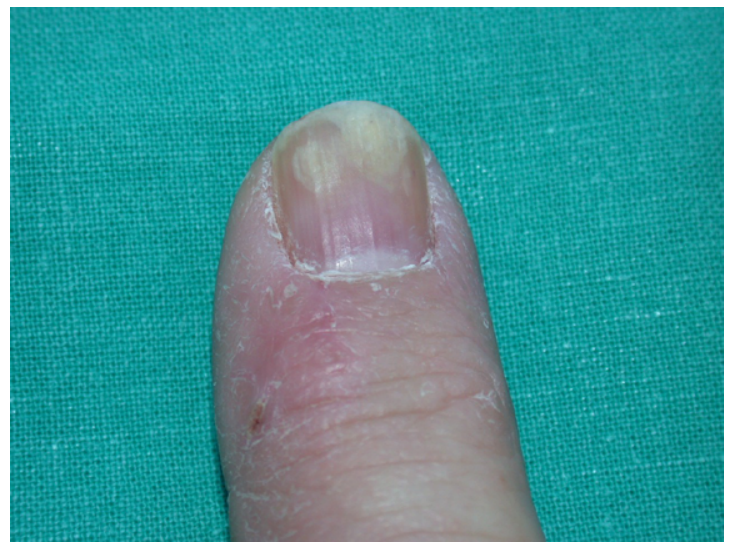


Pterigium: Adherencia entre el pliegue proximal y el lecho ungueal. Generalmente a consecuencia de los traumatismo, quemaduras y radiodermitis.

\section{Anomalías de la coloración:}

Cambios de coloración con o sin cambios inflamatorios. Pueden ocurrir como consecuencia de traumas externos, dermatitis de contacto (figura 4), infecciones, etc. Las consecutivas a traumas agudos pueden ocasionar una coloración oscura, que deberá llevar a realizar diagnostico diferencial con melanoma (figura 5).

Figura 4. Uña de trabajador que manipulaba sosa

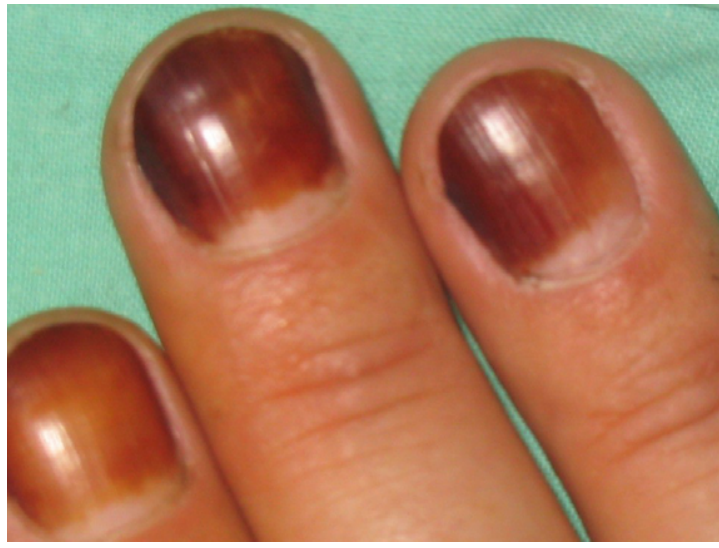

Figura 5. Uña traumática

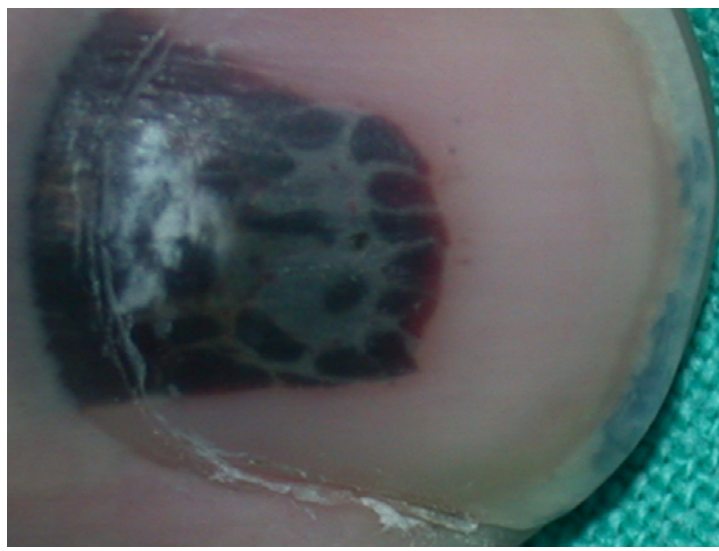

Anomalias de la superficie ungueal:

Uñas quebradizas: Se asocian frecuentemente con una onicosquicia (desdoblamiento transversal en capas en el borde libre de la uña) y la inmersión frecuente de las manos en agua.

Surcos: Depresiones transversas o longitudinales, consecutivos en muchas ocasiones a microtraumas que afectan a la lúnula.

Anomalias por infecciones:

Paroniquia: Inflamación de los tejidos periungueales, que pueden ser agudas (microorganismos aerobios y anaerobios) o crónicas (relacionada con humedad excesiva de las manos $)^{10}$.

A continuación se muestran las tablas 1 y 2 , que detallan las causas específicas de alteración ungueal y los mecanismos de su producción, respectivamente. 
Tabla I. Causas específicas de alteraciones ungueales

\begin{tabular}{|c|c|c|c|}
\hline Adhesión & Color & Forma & Superficie \\
\hline $\begin{array}{l}\text { Onicolisis: } \\
\text { Fluidos de } \\
\text { soldadura } \\
\text { Detergentes } \\
\text { Cianuro de } \\
\text { potasio } \\
\text { Ácido } \\
\text { hidrofluorúrico } \\
\text { Solventes } \\
\text { orgánicos } \\
\text { Aceites de } \\
\text { motor } \\
\text { Quaternium } 15\end{array}$ & $\begin{array}{l}\text { Blancas: Arsénico, Talio y } \\
\text { Plomo }{ }^{11}, \text { Sal, } \\
\text { Frío Humedad, } \\
\text { microtraumatismos } \\
\text { Amarillas: Resinas } \\
\text { Epoxi, pesticidas, } \\
\text { Sales de Cromo, } \\
\text { Colorantes, } \\
\text { formaldehido, Ac. } \\
\text { Nítrico } \\
\text { Marrones: } \\
\text { Permanganato de potasio, } \\
\text { Henna, } \\
\text { Tabaco, iodo, Hidroquinona, } \\
\text { hierro } \\
\text { Rojas: mercurio cromo } \\
\text { Negras: Nitrato de plata } \\
\text { Azules: Azul de metileno } \\
\text { Sulfato cúprico }\end{array}$ & $\begin{array}{l}\text { Coiloniquia: } \\
\text { Solventes } \\
\text { orgánicos (benceno, } \\
\text { tolueno) } \\
\text { Aceites } \\
\text { Ácidos } \\
\text { Traumas repetidos }{ }^{12}\end{array}$ & $\begin{array}{l}\text { Oniscosquicia }{ }^{13} \text { : } \\
\text { Solventes } \\
\text { orgánicos, } \\
\text { detergentes, agua } \\
\text { ácidos, bases }\end{array}$ \\
\hline
\end{tabular}

Tabla II. Afectación ungueal según mecanismo de producción

\begin{tabular}{lll}
\hline \multicolumn{1}{c}{ Físicas } & \multicolumn{1}{c}{ Químicas } & \multicolumn{1}{c}{ Agentes infecciosos } \\
\hline Vibraciones & Álcalis & Virus \\
Cuerpos extraños & Ácidos & Bacterias \\
Temperatura (frío/calor) & Formaldehídos & Hongos \\
Radiaciones Ionizantes & Aceites de motor y soldadura & \\
Quemaduras & Detergentes & \\
Traumatismos & Solventes orgánicos & \\
\hline
\end{tabular}

\section{Afectación profesional}

Entre las causas de enfermedad profesional están las físicas, como por el frío, las quemaduras, las radiaciones ionizantes, los cuerpos extraños y las de origen traumático. Esta última es la causa más frecuente, a manera de ejemplo tenemos: la distrofia ungueal en trabajadores de campo, el hematoma subungueal en jugadores del fútbol profesional, la leuconiquia transversa, onicorrexis en guitarristas, paquioniquia y uñas quebradizas en trabajadores con martillo vibratorio, uñas en vidrio de reloj en karatecas, oniscosquisis en cirujanos, onicolisis, etc. Por causas químicas, los expuestos a los álcalis, aminoetilenamide (contenido en fluidos de soldadura), formaldehídos, ácido fluorhídrico, solventes orgánicos, aceites de motor, cianuro de potasio, ácido oxálico, etc. Dentro de las causas biológicas están los hongos como dermatofitos y cándida, bacterias como pseudomonas y serratia y virus como poxvirus y herpes virus y papiloma (tabla III) ${ }^{14}$. 
Tabla III. Ejemplos de afectación y profesión

\begin{tabular}{ll}
\hline \multicolumn{1}{c}{ AFECTACIÓN } & \multicolumn{1}{c}{ OCUPACIón } \\
\hline Paroniquia & $\begin{array}{l}\text { Químicos y trabajadores de laboratorios, pintores, zapateros, } \\
\text { agricultores, empastadores de libros, mecánicos, carpinteros }\end{array}$ \\
Onicolisis & $\begin{array}{l}\text { Zapateros, dentistas, trabajadores expuestos a radiación, microondas, } \\
\text { manicuristas, granjeros, jardineros }\end{array}$ \\
Onicosquicia & $\begin{array}{l}\text { Peluqueras, manicuristas, operarios de manipulación productos } \\
\text { congelados, trabajadores en constante contacto con agua (cocineros, } \\
\text { camareros, trabajadores de lavanderías, etc.) }\end{array}$ \\
Onicosis infecciosa & Granjeros, agricultores, mineros, camareros \\
\hline
\end{tabular}

\section{REFERENCIAS BIBLIOGRÁFICAS}

1. Silva P Paulina, Vera K Cristián, Kolbach R Marianne, Fernández L Francisca. Sospecha de patologías sistémicas a través de alteraciones ungueales. Rev. méd. Chile. 2006 ; 134(2): 231-238.

2. Robert Baran, Francisco M Camacho, José María Mascaro. Onicología: Biología y Alteraciones de la Unidad Ungueal. Grupo Aula Médica, 2006.

3. OIT. Enciclopedia de la Salud y Seguridad en el Trabajo. Madrid: Comunidad de Madrid. Ministerio de Trabajo y Suntos Sociales; 1998.

4. Marren P, de Berker D, Dawber RP, Powell S. Occupational contact dermatitis due to quaternium 15 presenting as nail dystrophy. Contact Dermatitis 1991; 25: 253-255.

5. Dhir H, Hand dermatitis and nail disorders of the workplace. Clin Occup Environ Med. 2006; 5: $381-96$.

6. McGrath, E. J., Darvay, A. and Lovell, C. R. (2009), Nail dystrophy and fingertip dermatitis as a manifestation of methyl methacrylate allergic contact dermatitis in a cow hoof trimmer. Contact Dermatitis.2009; 60: 344 .

7. Tan, C. and Zhu, W.-Y. (2006), Humbnail lamellar onychoschizia in a tea-picker. International Journal of Dermatology, 45: 1390-1391.

8. Jelen, G. (2009), Nail-fold contact dermatitis from coffee powder. Contact Dermatitis. 2009; 60: 289-290.

9. Dawderber, R. Baran, D.de Berker. Enfermedades de las uñas. Editorial Edinsa. Madrid 2000; 11-15.

10. Baran R, Dawner R, Haneke E,Tosti, Bristow I, A Text Atlas of Nail Disorders [en linea]. United Kingdom. Martin Dunitz, a member of the Taylor \& Franc is Group. 2003.

11. S. Bel Pla, D. García Fernández, V. García-Patos Briones. Toxicodermias: etiología, patogenia y patrones clínicos. Jano Medicina y Humanidades. 2001; 61(1399): 35-41.

12. Dhir Hari. Hands dermatitis in nail disorders of the workplace. Clinic Occup Environ Med.2006; 5(2): 381-396.

13. Wallis MS, Bowen WR, Guin, JD, Pathogenesis of onychoschizia (lamellar dystrophy). J Am Acad Dermato. 1991; 24 (1): 44-48.

14. Kanerva L, Elsner P, Wahlberg J L, Maibach H I, Condensed Handbook of Occupational Dermatology. Heidelberg, Germany. Springer; 2004. 